\title{
Gastric inflammatory myofibroblastic tumor masquerading as a pancreatic cystic neoplasm
}

A 56-year-old man presented with epigastric pain since 2 weeks. Esophagogastroduodenoscopy (EGD) revealed a $3-\mathrm{cm}$ submucosal mass in the posterior wall of the gastric body. Abdominal ultrasound showed a multilocular cystic lesion $(10 \times$ $6 \times 9 \mathrm{~cm})$ in the pancreatic tail. Endoscopic ultrasound (EUS) confirmed a multicystic lesion arising from the pancreas (๑ Fig. 1).

The cysts were macrocystic in nature, ranging from $1 \mathrm{~cm}$ to $2 \mathrm{~cm}$ in size, and were intermixed with solid tumor. There was no evidence of internal calcifications or connection to the pancreatic duct. The EUS features were suggestive of a mucinous cystadenocarcinoma of the pancreas. However, a subsequent computed tomography scan revealed that the multirior wall of the stomach; this was confirmed on laparotomy ( $\bullet$ Fig. 2).

Macroscopically, the tumor was a lobulated, circumscribed mass with a mix of solid and cystic components ( $\bullet$ Fig. 3 ).

Histologically, it consisted of proliferating spindle cells in a fibromyxoid stroma, admixed with a moderate amount of mixed inflammatory cellular infiltrate, compatible with a gastric inflammatory myofibroblastic tumor (IMT).

IMTs are rare neoplasms in adults. Microscopically, they are composed of spindle cells with abundant cytoplasm on an inflammatory background [1]. The diagnosis of IMT is often difficult and there are locular lesion was arising from the poste-
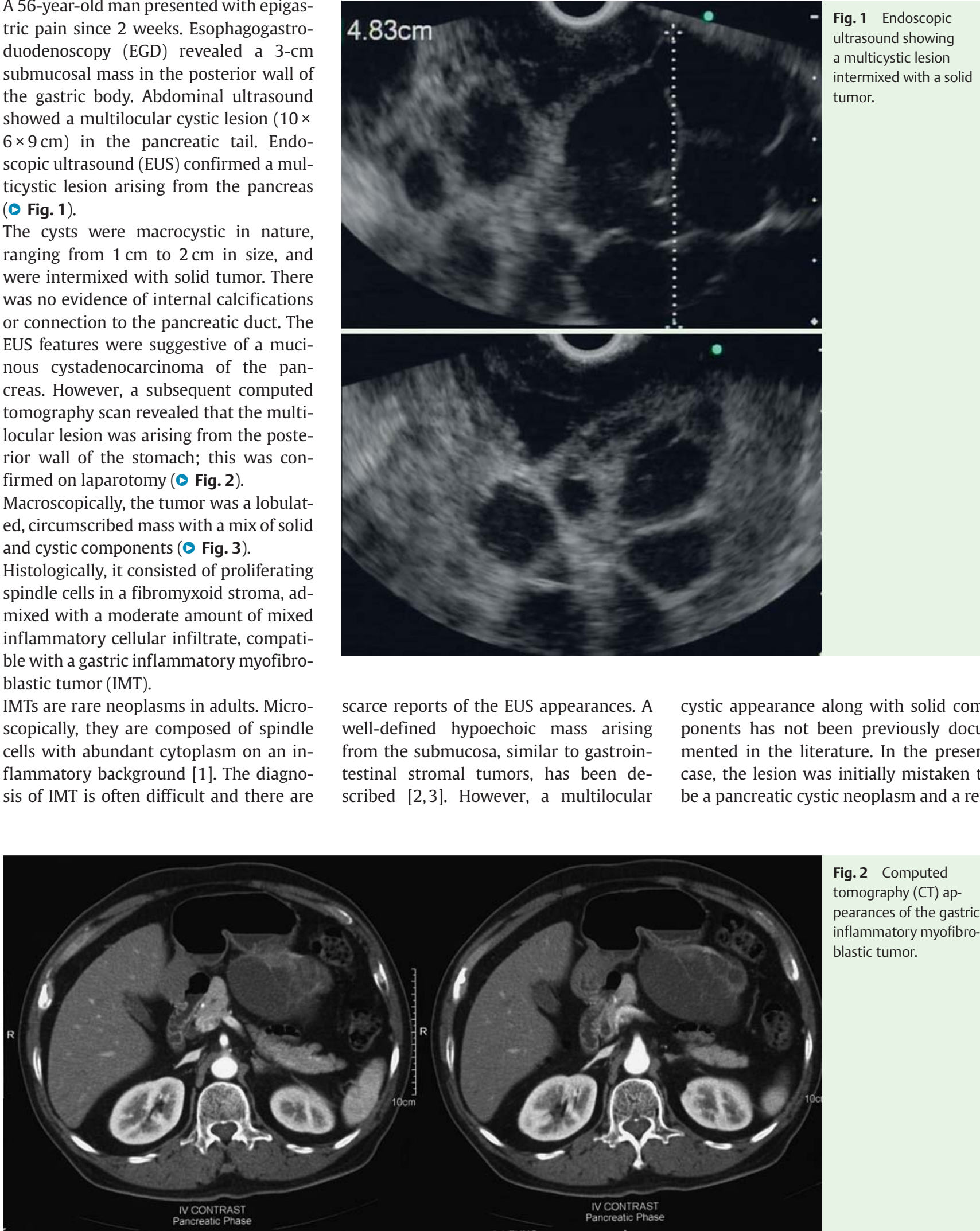

Fig. 2 Computed tomography (CT) appearances of the gastric inflammatory myofibroblastic tumor. 


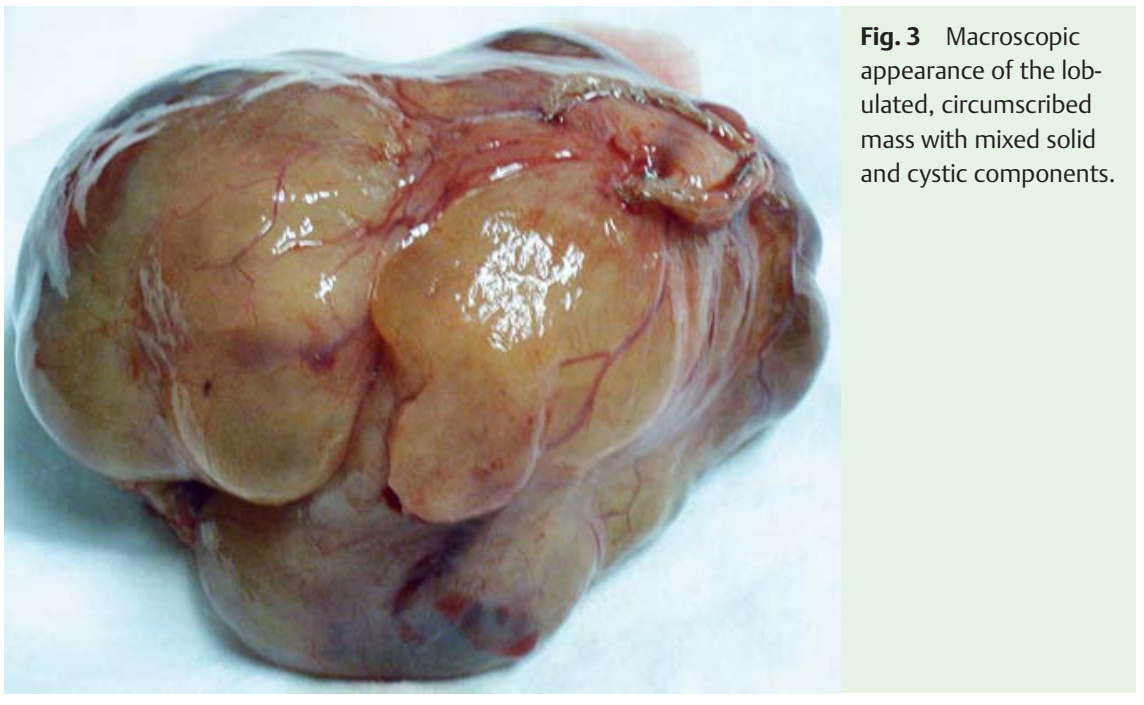

rospective review of the EUS images demonstrated that the tumor was indeed arising from the gastric wall. The mainstay of treatment for IMT is resection with clear margins [4,5]. After complete resection, the prognosis of IMT is generally good with a low risk of distant metastasis $[1,4,5]$.

\section{Competing interests: None}

Endoscopy_UCTN_Code_CCL_1AB_2AD_3AB

Endoscopy_UCTN_Code_CCL_1AF_2AZ_3AB

\section{A. K. W. Fong, A. Y. B. Teoh,}

P. W. Y. Chiu, S. K. H. Wong, E. K. W. Ng

Division of Upper Gastrointestinal Surgery, Department of Surgery, Prince of Wales Hospital, Chinese University of Hong Kong, Hong Kong SAR, China

\section{References}

1 Coffin CM, Watterson J, Priest JR et al. Extrapulmonary inflammatory myofibroblastic tumor (inflammatory pseudotumor). A clinicopathologic and immunohistochemical study of 84 cases. Am J Surg Pathol 1995; 19: $859-872$
2 Leon CJ, Castillo J, Mebold J et al. Inflammatory myofibroblastic tumor of the stomach: an unusual complication after gastrectomy. Gastrointest Endosc 2006; 63: 347-349

3 Shah SM, Sussman D, Jorda $M$ et al. EUS with EMR of an inflammatory myofibroblastic tumor of the stomach. Gastrointest Endosc 2008; 67: $561-563$

4 Difiore JW, Goldblum JR. Inflammatory myofibroblastic tumor of the small intestine. J Am Coll Surg 2002; 194: 502 - 506

5 Pungpapong S, Geiger XJ, Raimondo M. Inflammatory myofibroblastic tumor presenting as a pancreatic mass: a case report and review of the literature. JOP 2004; 5: 360 367

\section{Bibliography}

DOI $10.1055 / \mathrm{s}-0029-1244227$

Endoscopy 2010; 42: E231 -E232

(c) Georg Thieme Verlag KG Stuttgart · New York . ISSN 0013-726X

\section{Corresponding author}

\section{E. K. W. $\mathbf{N g}$}

Department of Surgery Prince of Wales Hospital

Shatin New Territories

Hong Kong SAR

China

Fax: +852-2637-7974

endersng@surgery.cuhk.edu.hk 